\title{
Analysis of Urban Functional Characteristics of Urban Agglomeration: A Case Study of Changsha-Zhuzhou-Xiangtan Urban Agglomeration
}

\author{
Jiayi Zhao \\ Institute of Economy, Jinan University, Guangzhou, China \\ Email: zhaojiayi215@outlook.com
}

How to cite this paper: Zhao, J. Y. (2017) Analysis of Urban Functional Characteristics of Urban Agglomeration: A Case Study of Changsha-Zhuzhou-Xiangtan Urban Agglomeration. Chinese Studies, 6, 71-84. https://doi.org/10.4236/chnstd.2017.62008

Received: April 7, 2017

Accepted: May 20, 2017

Published: May 23, 2017

Copyright $\odot 2017$ by author and Scientific Research Publishing Inc. This work is licensed under the Creative Commons Attribution-NonCommercial International License (CC BY-NC 4.0). http://creativecommons.org/licenses/by-nc/4.0/ cc) (i) (8) Open Access

\begin{abstract}
Bearing the responsibility of the rising strategy of central region of China, Changsha-Zhuzhou-Xiangtan Urban Agglomeration is an important growth pole of the development of the Yangtze river economic belt. Reasonable position of urban function in Changsha-Zhuzhou-Xiangtan Urban Agglomeration, is an inevitable requirement for the cooperative development of regional economy in Changsha, Zhuzhou and Xiangtan. This paper takes the basic economic activities of these cities as the starting point to determine the urban function. Subsequently, this paper uses the related statistical data, introduces multivariate statistical analysis method, such as regression analysis, factor analysis and cluster analysis to clarify the function of 20 cities in ChangshaZhuzhou-Xiangtan Urban Agglomeration. The findings reveal that the most common functions of the regional urban agglomeration are construction, transportation, postal services, finance, real estate, manufacturing, social services, wholesale and retail industry. At the same time, the paper classifies these 20 cities according to the urban function. The classification results provide the basis for accelerating Changsha-Zhuzhou-Xiangtan Urban Agglomeration construction of urban function.
\end{abstract}

\section{Keywords}

Functional Characteristics, Factor Analysis, Changsha-Zhuzhou-Xiangtan Urban Agglomeration

\section{Introduction}

Along with the rapid development of the modern world economy, economic 
globalization and regional economic integration become the two inevitable trends. Among these two major development trends, the core of economic competition power in various countries gradually has focused on the overall competitiveness of urban agglomeration (Sun Qian et al., 2015). Under the policy guidance of the central government to promote the rise of the middle area, Hunan province has emphasised on the development of Changsha-ZhuzhouXiangtan Urban Agglomeration in recent years. So the growth pole of Changsha-Zhuzhou-Xiangtan Urban Agglomeration is increasingly evident (Li Rui et al., 2014).

Changsha-Zhuzhou-Xiangtan Urban Agglomeration is an area that takes Changsha, Zhuzhou, Xiangtan as the center and one-hour highway distance between cities as commuting radius, including Yueyang, Changde, Yiyang, Loudi, Hengyang. Its total land area is 96,900 square kilometers, accounting for $45.8 \%$ of Hunan province. As the core area, the total area of Changsha, Zhuzhou, Xiangtan account for $13.3 \%$, and the total population accounts for $19.6 \%$ of $\mathrm{Hu}-$ nan Province. Besides, in 2014, the GDP of these 3 cities was 1155.587 billion yuan (Luo Haifan, 2007). Capital, labor force, technology and other important factors of production in Hunan province are concentrated together here. For such a regional urban agglomeration in the vigorous development, the reasonable industrial distribution of each city of this urban agglomeration and the clear function of the city play a key role in the speed and quality of the development of the whole Urban Agglomeration. At present, there are quite a lot of researches on the urban functions in theory circle, but it has not been found in the study of the urban function of the city group of Changsha-Zhuzhou-Xiangtan Urban Agglomeration. Based on this, this paper applies regression analysis, factor analysis and cluster analysis to study the functional structure of the inner city of Changsha-Zhuzhou-Xiangtan Urban Agglomeration qualitatively and quantitatively. And it will provide theoretical and practical guidance for the development direction and path of Changsha-Zhuzhou-Xiangtan Urban Agglomeration.

\section{Research Background}

1) The need to promote the development of urban agglomeration in the middle reaches of the Yangtze River. According to "the development plan of the urban agglomeration in middle reaches of the Yangtze River" released by National Development and Reform Commission, urban agglomeration in the middle reaches of the Yangtze River city group connects the south and the north, the west and the east, which occupies an important position in the regional development pattern of china. It is an important area in Yangtze Economic Zone as well as the key areas where 3 strategies are implemented: Promoting the rise of the middle region, Deepening reform and opening up in all direction and Promoting new urbanization. Urban agglomeration in the middle reaches of the Yangtze River is a large urban agglomeration which is constitute of the Wuhan Metropolitan Areas, the Poyang Lake Ecological Economic Zone and ChangshaZhuzhou-Xiangtan Urban Agglomeration, involving 31 city and 3 province: 
Hunan, Jiangxi and Hubei provinces. According to the national planning, urban agglomeration in the middle reaches of the Yangtze River will complete the integrated development mechanism. At the meanwhile, it also will promote collaborative development of urban and rural, industrial, infrastructure, ecological civilization and public service.

2) The need to play an exemplary role of Changsha-Zhuzhou-Xiangtan Urban Agglomeration. Since the establishment of special economic zones, new zones and comprehensive reform pilot area, the basic formation of the East Central and Western interactive development pattern is entering a new stage in national level. The current comprehensive reform of the national construction of the experimentation area basically formed the interactive development pattern of eastern, central and western regions. There is no special policy for comprehensive reform pilot area but only the priority right. The comprehensive reform pilot areas emphasized differently in specific tasks and the division of labor. Shanghai Pudong New Area, Tianjin Binhai New Area and the Shenzhen Special Economic Zone are regarded mainly to carry out a comprehensive exploration in how to accelerate the speed of the opening up and improve the socialist market economic system. Wuhan Metropolitan Areas and Changsha-Zhuzhou-Xiangtan Urban Agglomeration are set to carry out the reform test of a resource-saving and environment-friendly society. While Chongqing and Chengdu are focusing on the coordination of the development of urban and rural areas, and the reform theme of Shenyang economic zone is a new type of industrialization. Each of the comprehensive reform pilot areas has been exploring the key problems that restrict the development of economy and society, and has made positive progress and breakthroughs in transformation of government functions, adjustment of the industrial structure, reformation of financial system, cooperative development of urban and rural areas and construction of a resource-saving and environment-friendly society. The study on the functional characteristics of each city considered to be essential to the demonstration function of Changsha-ZhuzhouXiangtan Urban Agglomeration.

3) The need to promote the innovation in Changsha-Zhuzhou-Xiangtan Urban Agglomeration. Following Wuhan DonghuLake, Changsha-Zhuzhou-Xiangtan Urban Agglomeration has become the second national independent innovation demonstration zone in the central and western regions of china. With $3 \mathrm{Na}$ tional Development Zones for New and High Technology Industries, ChangshaZhuzhou-Xiangtan Urban Agglomeration gathered more than $70 \%$ of scientific research institutions, $70 \%$ of innovative business platform, $60 \%$ of high-tech enterprises and created $70 \%$ of scientific and technological achievements in Hunan province. Thus, it is an objective requirement for the innovation and development of Changsha-Zhuzhou-Xiangtan Urban Agglomeration to strengthen the combination of resources, promote the industry-university cooperative innovation and enhance the independent innovation ability based on the advantages in talent, achievements and platform. The result of the study also provides strong support to enhance the driving ability and competitiveness of Changsha-Zhuzhou-Xiangtan Urban Agglomeration. 


\section{Research Methods and Data Sources}

\subsection{Research Methods}

This paper takes the basic theory of urban economic as the theoretical basis for the analysis of urban functions and divides the function of cities according to the basic activity department. Firstly, grouping all cities according to the population scale, finding out the minimum proportion of employees in each department and the population of the medium scaled city, then doing regression analysis with the two sets of data of different department. Next, using the established regression equation to get the proportion of basic parts of different department in each city (Mao Jiangxing \& Ouyang Dong, 2008).

After separating the basic part of the employees from different departments in the city, a department structure that reflects the basic activities of the city is formed. Factor analysis is conducted to analyze the data matrix that takes each city as a sample and each functional department as variable. Then we draw out the main factors that reflect the information of urban functional structure, and get interpretation of the main factor load through the rotation of the factor axis. At last, we calculated the scores of urban function factors according to the results of factor analysis, and used cluster analysis method with factor scores to determine the type of urban functions. In short, the steps included are data collection and processing, urban functional feature extraction and comprehensive division of urban function types (Zeng Peng \& Luo Yan, 2013).

\subsection{Data Source and Arrangement}

According to the administrative division of Changsha-Zhuzhou-Xiangtan Urban Agglomeration, we takeda total of 20 cities as sample (including 8 prefecture level cities, 12 county-level cities): Changsha, Zhuzhou, Xiangtan, Hengyang, Yueyang, Yiyang, Changde, Loudi, Liuyang, Liling, Shaoshan, Xiangxiang, Miluo County, Yuanjiang, Jinshi, Lengshuijiang, Lianyuan, Changning, Linxiang and Leiyan. The statistical data of the total population, urban population, working population and its industrial structure from "Statistical yearbook of Hunan province 2015", are selected as the basis for the analysis and calculation of the classification of urban functions. At the same time, the original data and statistical caliber were selected and processed properly in order to get a clear classification result.

In "Statistical yearbook of Hunan province 2015", social economic activities are divided into 19 sectors, we removed and merged some data on the basis of this. First, as a national agricultural province, the population of Hunan in agriculture are beyond the average, which can not reflect the non-agriculture urban functions, so we removed the data of population in "agriculture, forestry, animal husbandry and fisheries industry". Then we retained 7 industries: mining, manufacturing, construction, transportation and postal services, finance, real estate, public management. In the meanwhile, we merged the other 11 industries :The production and supply of electricity, gas and water, water conservancy environment and public facilities management are merged into the social service indus- 
try; wholesale and retail, accommodation and catering, leasing and residential services, repairing and other services are merged into the wholesale and retail-accommodation and catering services industry; The information transmission, software and technology services, scientific research, education and health, social work and cultural, entertainment and sports are merged into the science and education industry. We eventually classified all the industry that reflect the different urban function into 10 departments.

\section{Process and Results of Analysis}

\subsection{Group the Cities}

The 20 cities in Changsha-Zhuzhou-Xiangtan Urban Agglomeration are divided into 5 groups by the number of urban population. The first group is Changsha, owning more than 4 million people; The second group includes Zhuzhou, Hengyang, Yueyang, and Changde, owning 2 - 4 million people; The third group includes Xiangtan, Yiyang and Loudi, owning $1-2$ million people; The fourth group includes Liuyang, Liling, Leiyang, Changning, Miluo and Yuanjiang, owning 300 thousand to 1 million people. While the last group only has the population of less than 300,000, including Xiangxiang, Shaoshan, Linxiang, Jinshi city, Lengshuijiang and Lianyuan.

\subsection{Calculate the Basic Proportion}

It is indicated that the result of city group is consistent with the requirements of continuous scale structure, so that it can be applicable to the Moore (C. L. Moore) regression analysis method (Xu Hongyu et al., 2005). The specific steps to determine the minimum requirements for each functional department are as follows:

First, deriving the parameters $a_{i}$ and $b_{i}$ from regression Equation (1). $E_{i j}$ means the actual minimum proportion of workers of $i$ department in $j$ city. $P_{j}$ means the urban population of medium city in $j$ group.

$$
E_{i j}=a_{i}+b_{i} \lg P_{j}
$$

Then, we get the optimal fitting regression equation of 10 department (Table 1) after the calculation of $a_{i}$ and $b_{i}$. The exact population number of each city are substituted into regression Equation (2) to calculate the minimum required amount of the $i$ department. $P$ means the number of non-agricultural population in each city. $E_{i}$ means the minimum required amount of $i$ department.

$$
E_{i}=a_{i}+b_{i} \lg P
$$

Subtracting the number of the minimum requirements from that of actual proportion of employees, eventually we get the basic proportion of the employees in each department.

\subsection{Factor Distilling}

Factor analysis method was conducted to the " $20 \times 10$ " matrix, which consists of 20 cities and the basic proportion of the employees in 10 departments, thereby 
Table 1. Regression fitting table of 20 cities in Changsha-Zhuzhou-Xiangtan Urban Agglomeration.

\begin{tabular}{|c|c|c|}
\hline & R-Squared & regression equation \\
\hline Mining industry & 0.685059 & $\mathrm{X} 1=-0.00307035205859+0.000551816459478 * \mathrm{Y}$ \\
\hline Manufacturing industry & 0.639162 & $\mathrm{X} 2=-0.0323656215786+0.00582613255473 * \mathrm{Y}$ \\
\hline Construction industry & 0.650493 & $\mathrm{X} 3=-0.0346914634307+0.00627244208295 * \mathrm{Y}$ \\
\hline $\begin{array}{c}\text { Transportation and postal } \\
\text { services industry }\end{array}$ & 0.739132 & $\mathrm{X} 4=-0.014478154305+0.00264168132964 * \mathrm{Y}$ \\
\hline Finance industry & 0.668848 & $\mathrm{X} 5=-0.00842361315341+0.00150858561933 * \mathrm{Y}$ \\
\hline Real estate industry & 0.469206 & $\mathrm{X} 6=-0.00637189194875+0.00113141040042 * \mathrm{Y}$ \\
\hline $\begin{array}{l}\text { Public management } \\
\text { industry }\end{array}$ & 0.834182 & $\mathrm{X} 7=-0.0350374957991+0.00790109486624 * \mathrm{Y}$ \\
\hline Social service industry & 0.581176 & $\mathrm{X} 8=-0.0487163061234+0.00869760931771 * \mathrm{Y}$ \\
\hline $\begin{array}{l}\text { Wholesaleand } \\
\text { retail-accommodation and } \\
\text { catering services industry }\end{array}$ & 0.742762 & $\mathrm{X} 9=-0.0174119774763+0.00316440422422 * \mathrm{Y}$ \\
\hline $\begin{array}{c}\text { Science and education } \\
\text { industry }\end{array}$ & 0.774283 & $\mathrm{X} 10=-0.107857501278+0.0216359391949 * \mathrm{Y}$ \\
\hline
\end{tabular}

we extract 4 main factors that covered $91.9 \%$ of the information in structure of these cities' basic department. After orthogonal rotation of the matrix, the contribution rate of each main factor and the table of factor load (Table 2) are obtained. Through the analysis of the factor load, characteristics of the structure of the basic part of these cities can be explained clearly (Chen Zhongnuan \& Yan Xiaopei, 2015).

From Table 2, The eigenvalue of the first main factor F1 is 6.741, and the Variance Contribution Rate reaches $67.415 \%$. The load of Mining industry, transportation and postal services industry, construction industry and finance industry are of high level in F1. The loading value of the factor is all above 0.75 in these 4 industry, F1 is regarded to reflecting the degree and level of urbanization and can be seen as the city's industrial transport and financial functions, which is the most common factor in the urban system of Changsha-Zhuzhou-Xiangtan Urban Agglomeration. The load of real estate industry, wholesale and retail-accommodation and catering services industry, social service industry and science and education industry is high in F2. They all reach the rate at above $60 \%$. The contribution rate of the variance is at $12.233 \%$ and the second main factor F2 reflects the city's science and education and business services functions. The load of manufacturing industry is high in the third main factor F3. It can be regarded as the manufacturing industry function factor. Its importance diminished and only made a contribution of $8.034 \%$. The contribution rate of the last main factor is less than $5 \%$ and can be seen as the management and organizational functions, the load of public management industry and social service industry is high in F4.

From the interpretation of the main factor above, the most common functions 
Table 2. Contribution rate and factor load of each main factor after Orthogonal rotation.

\begin{tabular}{|c|c|c|c|c|}
\hline Project & Main factor 1 & Main factor 2 & Main factor 3 & Main factor 4 \\
\hline Eigenvalue & 6.741 & 1.223 & 0.803 & 0.426 \\
\hline Variance Contribution Rate\% & 67.415 & 12.233 & 8.034 & 4.265 \\
\hline $\begin{array}{l}\text { Accumulated Variance } \\
\text { Contribution Rate } \%\end{array}$ & 67.415 & 79.648 & 87.682 & 91.947 \\
\hline Functional departments & \multicolumn{4}{|c|}{ factor load } \\
\hline Proportion of mining industry & 0.923 & 0.021 & 0.098 & 0.277 \\
\hline $\begin{array}{l}\text { Proportion of transportation } \\
\text { and postal services industry }\end{array}$ & 0.855 & 0.323 & 0.275 & 0.110 \\
\hline $\begin{array}{l}\text { Proportion of construction } \\
\text { industry }\end{array}$ & 0.806 & 0.286 & 0.279 & 0.080 \\
\hline Proportion of finance industry & 0.790 & 0.508 & 0.202 & 0.081 \\
\hline $\begin{array}{l}\text { Proportion of real } \\
\text { estate industry }\end{array}$ & 0.126 & 0.893 & 0.321 & 0.088 \\
\hline $\begin{array}{l}\text { Proportion of wholesale and } \\
\text { retail-accommodation and } \\
\text { catering services industry }\end{array}$ & 0.260 & 0.829 & -0.081 & 0.292 \\
\hline $\begin{array}{l}\text { Proportion of social } \\
\text { service industry }\end{array}$ & 0.478 & 0.714 & 0.466 & -0.059 \\
\hline $\begin{array}{l}\text { Proportion of science } \\
\text { and education industry }\end{array}$ & 0.417 & 0.609 & 0.554 & 0.336 \\
\hline $\begin{array}{c}\text { Proportion of manufacturing } \\
\text { industry }\end{array}$ & 0.244 & 0.143 & 0.899 & 0.152 \\
\hline $\begin{array}{l}\text { Proportion of public } \\
\text { management industry }\end{array}$ & 0.395 & 0.415 & 0.419 & 0.691 \\
\hline
\end{tabular}

of cities in Changsha-Zhuzhou-Xiangtan Urban Agglomeration are reflected in mining, transportation and postal services, construction and finance. Real estate, wholesale and retail-accommodation and catering services, social service and science and education are the second common function reflected, followed by manufacturing functions, and finally the public management and social service function.

\subsection{Divide Different Types}

For these 20 cities, the 4 main factors extracted before have different significance in them. Similar cities can be classified according to these differences (Table 3). We summed up the characteristics to form the specific functional categories.

According to the scores of 4 main factors of these 20 cities, the matrix of score was established. The cluster analysis method is used to carry out the multi-variable cluster analysis. And the classification of different urban functions is obtained. The same function characteristic of different type of cities can be summarized. Finally, all cities are divided into 6 major categories, 7 sub categories (Table 4). 
Table 3. Scores of main factor of 20 cities in Changsha-Zhuzhou-Xiangtan Urban Agglomeration.

\begin{tabular}{|c|c|c|c|c|}
\hline City & $\mathrm{F} 1$ & F2 & F3 & $\mathrm{F} 4$ \\
\hline Changsha & 0.153520093 & 1.218637451 & 0.317910063 & -2.140313164 \\
\hline Zhuzhou & -0.353770012 & -0.718831764 & 0.078897076 & 0.290095426 \\
\hline Hengyang & -0.447973881 & -1.402550108 & -0.640010617 & 0.529442707 \\
\hline Yueyang & -0.253742892 & -1.089710667 & -0.40844353 & 0.412251869 \\
\hline Changde & -0.574955815 & -0.453771479 & -1.410130385 & 0.760793048 \\
\hline Xiangtan & -0.02700485 & -0.866590623 & 0.219461533 & -0.003847826 \\
\hline Yiyang & -0.414196171 & -0.440743321 & -1.014990062 & 0.937592571 \\
\hline Loudi & -0.033967235 & -1.363323626 & 0.179844962 & 0.369243919 \\
\hline Liuyang & -0.565052731 & -0.141402503 & -0.162423168 & -0.649790208 \\
\hline Liling & -0.391727726 & 0.006295437 & 0.200281288 & -1.000668349 \\
\hline Leiyang & 0.059258332 & 0.197490563 & -0.336288622 & -0.913907339 \\
\hline Changning & -0.10209592 & -0.115376937 & 0.013343893 & -0.224002518 \\
\hline Miluo & 0.44840842 & 0.53708712 & -0.48067165 & -0.086850929 \\
\hline Yuanjiang & 0.019748039 & 0.329464761 & 0.91526297 & -0.558510744 \\
\hline Linxiang & -0.144714341 & 0.541960908 & -0.668770242 & -0.813924392 \\
\hline Jinshi & -0.50616252 & 2.109219005 & 0.646483536 & 2.875708286 \\
\hline Xiangxiang & -0.75566981 & -0.302963198 & 3.465650213 & 0.189988379 \\
\hline Shaoshan & -0.215664997 & 2.336135516 & -0.969623093 & 0.00254366 \\
\hline Lengshuijiang & 4.06170332 & -0.191632482 & 0.301890101 & 0.600886275 \\
\hline Lianyuan & 0.044060697 & -0.189394053 & -0.247674264 & -0.576730675 \\
\hline
\end{tabular}

Table 4. Categories of urban functions of 20 cities in Changsha-Zhuzhou-Xiangtan Urban Agglomeration.

\begin{tabular}{ccc}
\hline Major categories & Sub categories & Name of city \\
\hline I & & Lengshuijiang \\
II & Xiangxiang \\
III & Jinshi \\
IV & $\mathrm{IV}_{1}$ & Changsha \\
& $\mathrm{IV}_{2}$ & Shaoshan \\
$\mathrm{V}$ & $\mathrm{V}_{1}$ & Hengyang Yueyang Zhuzhou Xiangtan Loudi \\
& $\mathrm{V}_{2}$ & Changde Yiyang \\
& $\mathrm{VI}_{1}$ & Yuanjiang \\
& $\mathrm{VI}_{2}$ & Miluo Linxiang Leiyang \\
VI & $\mathrm{VI}_{3}$ & Liuyang Liling Changning Lianyuan \\
\hline
\end{tabular}

\subsection{Explanation}

According to the scores of 4 main factors of each major categories and sub categories (Table 5), we can analyze the representative factors in order to explain the various categories. Through the comparative analysis on Table 5, the categories of urban function are interpreted as follows: 
Table 5. Score of main factor in various categories.

\begin{tabular}{cccccc}
\hline $\begin{array}{c}\text { Major } \\
\text { categories }\end{array}$ & $\begin{array}{c}\text { Sub } \\
\text { categories }\end{array}$ & \multicolumn{5}{c}{ Score of main factor (mean value) } \\
\hline I & & 1 & 2 & 3 & 4 \\
\hline II & & 4.06170332 & -0.191632482 & 0.301890101 & 0.600886275 \\
III & & -0.75566981 & -0.302963198 & 3.465650213 & 0.189988379 \\
& & -0.50616252 & 2.109219005 & 0.646483536 & 2.875708286 \\
IV & $\mathrm{IV}_{1}$ & 0.153520093 & 1.218637451 & 0.317910063 & -2.140313164 \\
& $\mathrm{IV}_{2}$ & -0.215664997 & 2.336135516 & -0.969623093 & 0.00254366 \\
$\mathrm{~V}$ & $\mathrm{~V}_{1}$ & -0.223291774 & -1.088201358 & -0.114050115 & 0.319437219 \\
& $\mathrm{~V}_{2}$ & -0.494575993 & -0.4472574 & -1.212560223 & 0.84919281 \\
& $\mathrm{VI}_{1}$ & 0.019748039 & 0.329464761 & 0.91526297 & -0.558510744 \\
$\mathrm{VI}$ & $\mathrm{VI}_{2}$ & 0.120984137 & 0.425512864 & -0.495243505 & -0.60489422 \\
& $\mathrm{VI}_{3}$ & -0.25370392 & -0.109969514 & -0.049118063 & -0.612797937 \\
\hline
\end{tabular}

From Table 5, it is known that the score of the first main factor F1 is the highest in cities divided into the I category, which means that the industrial transport and financial functions of this type are the most prominent among these cities. As an important industrial city in Hunan Province, Lengshuijiang is famous for its antimony, steel, chemical, thermal power, building materials and coal industry. As it is rich in mineral resources, mining industry becomes the traditional advantage industry here. Lengshuijiang is known as the world's antimony capital because it produces around 60 per cent of global supplies.

The score of the first main factor F1 is the highest in cities divided into the I category, which means that the industrial transport and financial functions of this type are the most prominent among these cities. As a county-level city, the leading industry is the second industry in Xiangxiang, especially the manufacturing industry, including metallurgy, building materials, chemical industry, electronics, electric power, machinery and so on. The main products of this city are cement, iron alloy, aluminum fluoride and chemical fertilizers. ShaoFengcement company is one of the most important cement enterprises in China.

The III kind of city takes the fourth factor as the most important function factor. The score of management organization function is the highest. Besides, science and education industry, real estate industry and commercial services industry also occupy a large proportion. Jinshi city was a famous industrial city in Hunan Province, but the disappear of waterway advantage caused the rigidity of its institutional mechanism and stagnancy of development after 1970s. Nowadays, the proportion of the primary, secondary and tertiary industries is equivalent in Jinshi city, Its scenic spots made it become a tourist resort. It also does well in public administration and construction, and has won many national honor, such as the excellent national city of traffic management, the national advanced counties of legal publicity and education, the national counties of pension service and social demonstration.

The score of positive load is the highest in the second main factor in the IV 
kind of city. It shows that this kind of city takes science and education industry, commercial, real estate and services industry as main functions, while the production function does not reflect much. Besides, the score of the negative load of fourth factor is also very high in $\mathrm{IV}_{1}$, the function of social management organization is more prominent comparing with $\mathrm{IV}_{2}$. It fully reflects the cultural and administrative functions of Changsha as the core city in Changsha-ZhuzhouXiangtan Urban Agglomeration and the capital of Hunan Province. It sets function of politics, economy, culture, science and technology, finance, transportation, and information as one. As a county-level city, the population size and administrative area are small in Shaoshan, it is tourism that promotes the prosperity of its business and services industry. While other industrial industries are not developed.

In the $\mathrm{V}$ kind of city, the score of each function factor is more balanced. The positive load is the highest in the fourth factor F4, and the other factors all get negative load score. The negative load of $\mathrm{F} 2$ factor score of $\mathrm{V}_{1}$ type city is in the middle level. It shows that the function of this type of city is comprehensive. The comprehensive of two types of cities reflected in different way, so it can be divided into two sub categories: in the $\mathrm{V}_{1}$ kind of city, the score of negative load is high in the second factor, indicating that the real estate business services are relatively prominent. While the $\mathrm{V}_{2}$ City gets high score in the negative load of second factor, there is more advantage in the manufacturing sector. As the country's old industrial base as well as the emerging industrial city, the manufacturing industry is developed in Zhuzhou. This city, known as "the city pulled by train", takes metallurgy, machinery, chemical industry, new materials, bio pharmaceutical as the pillar. Meanwhile, it is also better than other cities in traffic functions. Xiangtan is an important industrial city in the central and southern regions. Its metallurgical, mechanical and electrical and military industry occupies an important position across the country. By the way of contrast, the function of the manufacturing industry is more obvious, but the functions of transportation and social management are backward. Hengyang located on the verge of Xiangjiang River, multiple railway lines and major highway intersect here. It is not only an important place to undertake processing trade industry, but also the demonstration zone to carry on industrial transfer. Being famous for rich products, Yueyang has a good location and soft power of culture, industry also is developed well here. It develops balancedly and rapidly in each aspect and can be regarded as a general comprehensive city. Among the cities of type $V_{2}$, Changde, Yiyang get high score in the positive load of the fourth factor and the negative load of the third factor. Yiyang is in the name of "little town of non-ferrous metals" and "a land of fish and rice", Changde is rich in resources. Its overall strength is in the forefront of Hunan province. Even the first Bus Rapid Transit (BRT) system in Hunan is constructed here. It indicates that cities of $\mathrm{V}_{2}$ type are comprehensive cities that are outstanding in manufacturing and social management. In general, the city of $\mathrm{V}$ type includes the core city of Chang Zhu Tan and the other five cities of the " $3+5$ " urban agglomeration. This type of city is a re- 
gional economic central city.

The VI type of city has small population scale in the region, including 9 county-level cities. Most county-level cities are dominated by the traditional industries such as agriculture, meanwhile industry, agricultural and business. Its infrastructure and urban function begin to take shape but not be perfect. The urban functions reflected by the first main factor are not noticeable. It has not yet formed an advantageous industry. The matching production and service sector and commercial trade sector are also not developed. The total high score of the fourth main factors is only because the city number of this category is more than that of others. Taking Yuanjiang as an example, the score of the third factor was high, but the score of the first factor was the lowest among the 20 cities. As an important export base of agricultural and sideline products in Hunan Province, Yuanjiang lacks of mineral resources. Its industry is based on agricultural resources. Liuyang and Liling have strong comprehensive strength. Its traffic construction and organizational management functions are stronger than that of other county-level cities, their manufacturing industry are based on the production of fireworks and other traditional industries.

\section{Countermeasures and Suggestions}

According to the classification of urban functions in Changsha-Zhuzhou-Xiangtan Urban Agglomeration, the functions of the 20 cities have significant differences and present hierarchical distribution. But comparing the current status of each city with their orientation and development direction, which were put forward in "Regional planning of Changsha-Zhuzhou-Xiangtan Urban Agglomeration (2008-2020)", we can see a certain gap between them (Table 6).

In order to improve the division of labor among the urban functions and promote the development of Changsha-Zhuzhou-Xiangtan Urban Agglomeration, the following measures can be taken to the construction of urban functions of Changsha-Zhuzhou-Xiangtan Urban Agglomeration.

1) The functional orientation of 3 central cities, Changsha, Zhuzhou and Xiangtan. As the only center of Changsha-Zhuzhou-Xiangtan Urban Agglomeration, the development of city in Changsha is relatively perfect, especially in real estate, business, services, education and science, public management and social organization industry, while industrial, transportation and manufacturing function is relatively weak. Xiangtan, Zhuzhou are two sub-center of Changsha-Zhuzhou-Xiangtan Urban Agglomeration, they located near the core city Changsha. As the old industrial city, the industrial cities' dominent characteristics are obvious, especially in manufacturing functions. Public management, social organization and traffic function are not so obvious. Zhuzhou is taken as a transportation hub of Hunan, the transportation function here is strong. It developed better than Xiangtan due to the better liquidity and population, except for manufacturing function. Given a full play to the different functional advantage of these 3 cities, strengthen varies with social management and promotes the development of the third industry with supporting system. And facilities will 
Table 6. The gap between current situation and planning of some important cities.

\begin{tabular}{|c|c|c|c|c|c|}
\hline $\begin{array}{c}\text { Major } \\
\text { categories }\end{array}$ & $\begin{array}{l}\text { Sub } \\
\text { categories }\end{array}$ & City & Current function & $\begin{array}{l}\text { Orientation in "Regional planning of } \\
\text { Changsha-Zhuzhou-Xiangtan Urban } \\
\text { Agglomeration (2008-2020)" }\end{array}$ & Disparity \\
\hline II & & Xiangxiang & Manufacturing function & $\begin{array}{l}\text { Important industrial base and } \\
\text { leisure tourism city }\end{array}$ & $\begin{array}{l}\text { Business and service } \\
\text { functions }\end{array}$ \\
\hline \multirow[t]{2}{*}{ IV } & $\mathrm{IV}_{1}$ & Changsha & $\begin{array}{l}\text { Comprehensive city focus } \\
\text { on commercial, real estate, } \\
\text { services, education, health } \\
\text { and social management } \\
\text { functions }\end{array}$ & $\begin{array}{l}\text { Core city of urban agglomeration, } \\
\text { advanced manufacturing center, } \\
\text { science and technology culture center, } \\
\text { logistics center and technology } \\
\text { innovation center. }\end{array}$ & $\begin{array}{l}\text { Industrial transport, } \\
\text { manufacturing functions }\end{array}$ \\
\hline & $\mathrm{IV}_{2}$ & Shaoshan & $\begin{array}{l}\text { commercial, real estate, } \\
\text { services, education } \\
\text { and health functions }\end{array}$ & $\begin{array}{l}\text { Famous tourist city, base of red } \\
\text { tourism service. }\end{array}$ & Basically conform \\
\hline \multirow{6}{*}{$\mathrm{V}$} & \multirow{5}{*}{$\mathrm{V}_{1}$} & Hengyang & & $\begin{array}{l}\text { The central city and transportation } \\
\text { hub in southern of Hunan, the } \\
\text { comprehensive manufacturing base. }\end{array}$ & Transport function \\
\hline & & Yueyang & Generally Balanced city & $\begin{array}{l}\text { Door of north Hunan, petrochemical } \\
\text { industry base, energy base, an } \\
\text { important node in the middle } \\
\text { reaches of the Yangtze River }\end{array}$ & Basically conform \\
\hline & & Zhuzhou & $\begin{array}{l}\text { Real estate, business, } \\
\text { services, industrial } \\
\text { transport and } \\
\text { financial functions }\end{array}$ & $\begin{array}{l}\text { Sub-center city of urban agglomeration, } \\
\text { advanced manufacturing and science, } \\
\text { technology, culture center. Logistics } \\
\text { center, technology innovation center. }\end{array}$ & Manufacturing function \\
\hline & & Xiangtan & $\begin{array}{l}\text { Real estate business } \\
\text { services, and } \\
\text { manufacturing functions }\end{array}$ & $\begin{array}{l}\text { Sub-center city of urban agglomeration, } \\
\text { advanced manufacturing and science, } \\
\text { technology, culture center. Logistics } \\
\text { center, technology innovation center. }\end{array}$ & $\begin{array}{l}\text { Social management, } \\
\text { traffic and building } \\
\text { functions }\end{array}$ \\
\hline & & Loudi & $\begin{array}{l}\text { Business and service } \\
\text { functions }\end{array}$ & $\begin{array}{l}\text { An important node that expanded } \\
\text { its functions to the central and west } \\
\text { of Hunan, anenergy base. }\end{array}$ & $\begin{array}{l}\text { Industrial and } \\
\text { transportation functions }\end{array}$ \\
\hline & $\mathrm{V}_{2}$ & Changde & $\begin{array}{l}\text { Comprehensive city focus } \\
\text { on manufacturing } \\
\text { function and public } \\
\text { management } \\
\text { organization function }\end{array}$ & $\begin{array}{l}\text { Central city in Northwest of Hunan, } \\
\text { transportation hub, an important } \\
\text { base for manufacturing and } \\
\text { agricultural products processing. } \\
\text { New energy and leisure travel } \\
\text { service base }\end{array}$ & $\begin{array}{l}\text { Business and } \\
\text { service functions }\end{array}$ \\
\hline VI & $\mathrm{V}_{\mathrm{I} 2}$ & Liling & $\begin{array}{l}\text { Public management } \\
\text { organization, financial, } \\
\text { industrial and traffic } \\
\text { functions }\end{array}$ & $\begin{array}{l}\text { Ceramic City, door of east Hunan, } \\
\text { traditional industrial base }\end{array}$ & $\begin{array}{l}\text { Manufacturing, business } \\
\text { and service functions }\end{array}$ \\
\hline
\end{tabular}

be much helpful to the cities' center functions and the economic radiation ability of the whole urban agglomeration. The future orientation of three cities are below: changsha should take High-tech industry as its leading industry, and mainly develop Manufacturing and service industry. Zhuzhou should build a equipment manufacturing base of rail transit, and stress the advantage industry such as 
processing of non-ferrous metals, chemical industry and ceramic industry. Thus it is easier to achieve the goal of Xiangtan to be constructed as the advanced manufacturing center, modern logistics center and ecological leisure center and play a leading role of the core city. Finally it will become the engine in Rising of the central regions (Luo Haifan, 2007).

2) The functional orientation of 5 prefecture level cities, Yueyang, Changde, Yiyang, Loudi, and Hengyang. The government of Hunan province also proposed " $3+5$ " network urban agglomerations system when planning the development of Changsha-Zhuzhou-Xiangtan Urban Agglomeration. Those are cities within 1.5 hours commuting radius from Changsha, Zhuzhou and Xiangtan, including Yueyang, Changde, Yiyang, Loudi, Hengyang. These 5 cities are showing the characteristics of the comprehensive unban function, reflecting the great vitality and potential. Hengyang, Yueyang and Loudi have obvious function in commercial, real estate, health and service. Yiyang and Changde are more prominent in manufacturing and public management functions. However, the five cities are generally underdeveloped in the functions of industry, transportation and finance. The process of industrialization needs to be accelerated. It is necessary to cultivate the comprehensive urban functions and make balanced development of all aspects. Particularly Hengyang and Changde, are ought to strengthen the function of transport so that they can play the main role of the regional central city and transport hub. The " $3+5$ " urban agglomeration is the best region in economic development level, traffic location and resource conditions all over the province. The development plan of Hunan province is to promote the economic integration of Changsha, Zhuzhou and Xiangtan, and build the Changsha-Zhuzhou-Xiangtan Urban Area, Changsha-Zhuzhou-Xiangtan Urban Circle, and the Changsha-Zhuzhou-Xiangtan Urban Agglomeration gradually at the same time. This concept of development is consistent with the current distribution of ladder that cities of Changsha-Zhuzhou-Xiangtan Urban Agglomeration are descending from core to periphery in function differentiation and industrialization degree.

3) The functional orientation of 12 County-level cities. In the 12 county-level cities, Lengshuijiang, Shaoshan, Xiangxiang, jinshi show more obvious features. And the functional characteristics they show fit the positioning in the plan of urban development. Taking Xiangxiang and Liling as an example, Xiangxiang has prominent function of manufacturing, but it is necessary to strengthen the supporting functions of tourism services such as commercial and service industry, striving to build itself into an important industrial base and leisure tourism city in Changsha-Zhuzhou-Xiangtan Urban Agglomeration. Liling should vigorously develop the ceramics, fireworks and other traditional industries, and enhance the proportion of commercial services. Then it should demonstrate the door of east Hunan's style. The other 9 county-level cities' urban function are still not that clear, there is no specific functional division of labor, mostly developing traditional industries in the foundation of natural resources advantages. According to the statistical yearbook of Hunan Province 2013, the city's appar- 
ent per capita GDP in cities with prominent functional characteristics, such as Liuyang, Liling, Xiangxiang and Shaoshan, isgenerally higher than cities whose functional characteristics are not obvious. So it is critical for the county-level city to find their own urban function position. Municipal Government should focus on their own characteristics and advantages of industries to create their own characteristics, such as mining resources, energy processing, tourism and so on. For example, there are many kinds of coal, metal and nonmetal mineral resources in Leiyang, and the output is large, so Leiyang can greatly develop the extractive industry and highlight the function of energy industry.

\section{References}

Chen Zhongnuan, \& Yan Xiaopei 陈忠暖, 阎小培 (2001). Characteristics and Classification of Urban Functions of 6 Provinces in the Southeast of China 中国东南 6 省区城 市职能特点与分类. Economic Geography, 21, 709-713. (In Chinese)

Li, R., Guo, Q., Wu, D., Yin, H., Zhang, H., \& Zhu, T. (2014). Spatial Characteristics of Development Efficiency for Urban Tourism in Eastern China: A Case Study of Six Coastal Urban Agglomerations. Journal of Geographical Sciences, 24, 1175-1197. https://doi.org/10.1007/s11442-014-1146-7

Luo Haifan 罗海藩 (2007). Transformation of Chang Zhu Tan City Group 长株潭城市 群转型 (pp. 82-87). Beijing: Social Science Literature Press. (In Chinese)

Mao Jiangxing, \& Ouyang Dong 毛蒋兴, 欧阳东 (2008). Research on Urban Functional Structure Characteristics and Classification Based on Multivariate Statistical Analysis: Take Guangxi as an Example 基于多元统计分析的城市职能结构特征与分类研究: 以广西为例. Planners, 24, 75-80.

Sun, Q., Tang, F., \& Tang, Y. (2015). An Economic Tie Network-Structure Analysis of Urban Agglomeration in the Middle Reaches of Changjiang River Based on SNA. Journal of Geographical Sciences, 25, 739-755.

https://doi.org/10.1007/s11442-015-1199-2

Xu Hongyu, Chen Zhongnuan, \& Li Zhiyong 徐红宇, 陈忠暖, 李志勇 (2005). Survey of Urban Functional Classification in China 中国城市职能分类研究综述. Study on the Geographical Environment of Yunnan, 17, 33-36. (In Chinese)

Zeng Peng, \& Luo Yan 曾鹏, 罗艳 (2013). A Comparative Study on the Function and Structure of the Ten Major City Groups in China 中国十大城市群城市职能结构特征 比较研究. China Science and Technology Forum, 1, 103-107+114. (In Chinese) 
Submit or recommend next manuscript to SCIRP and we will provide best service for you:

Accepting pre-submission inquiries through Email, Facebook, LinkedIn, Twitter, etc. A wide selection of journals (inclusive of 9 subjects, more than 200 journals)

Providing 24-hour high-quality service

User-friendly online submission system

Fair and swift peer-review system

Efficient typesetting and proofreading procedure

Display of the result of downloads and visits, as well as the number of cited articles Maximum dissemination of your research work

Submit your manuscript at: http://papersubmission.scirp.org/

Or contact chnstd@scirp.org 